\title{
Appropriate Route Selection for Extracardiac Total Cavopulmonary Connection in Apicocaval Juxtaposition
}

\author{
Sei Morizumi, MD, Hideyuki Kato, MD, Shinya Kanemoto, MD, PhD, Mio Noma, MD, PhD, \\ Masakazu Abe, MD, PhD, Yuzuru Sakakibara, MD, PhD, and Yuji Hiramatsu, MD, PhD \\ Department of Cardiovascular Surgery, Faculty of Medicine, \\ University of Tsukuba, Tsukuba, Japan
}

\section{Running Head; TCPC IN APICOCAVAL JUXTAPOSITION}

Keywords; CHD-Fontan, CHD-univentricular heart, Outcomes

Word Count; 3486 words

\section{Address for correspondence:}

Yuji Hiramatsu, MD, PhD

Department of Cardiovascular Surgery,

Faculty of Medicine, University of Tsukuba

1-1-1 Tennodai, Tsukuba 305-8577, Japan

Tel; +81298533210

Fax; +81 298533097

e-mail: yuji3@md.tsukuba.ac.jp 


\section{[Abstract]}

Background. A malpositioned heart with apicocaval juxtaposition may complicate the management of patients with functional single ventricles when total cavopulmonary connection is performed. We reviewed our experience with extracardiac total cavopulmonary connection in patients with apicocaval juxtaposition with a special focus on route selection and outcomes.

Methods. Out of 68 patients who underwent extracardiac total cavopulmonary connection at our hospitals, 10 patients with apicocaval juxtaposition were included in this study. The mean follow-up was $40 \pm 28$ months. Patient demographics were compared with data on patients without apicocaval juxtaposition.

Results. The age at operation was $8 \pm 7$ years. We carefully chose conduit routes to create satisfactory fluid dynamics. The conduit was placed between the inferior vena cava and the ipsilateral pulmonary artery in 2 patients, and the conduit crossed midline in 8 . The mean postoperative pulmonary artery pressure was $13 \pm 2$ mmHg. The surgical and postoperative data were not significantly different when compared with the patients without apicocaval juxtaposition. There were no conduit-related early or late complications except for one patient who had poor ventricular function.

Conclusions. Extracardiac total cavopulmonary connection in apicocaval juxtaposition can be carried out with favorable mid-term outcomes. The route between the inferior vena cava and the contralateral pulmonary artery should be the primary choice when the relevant pulmonary artery is in good shape. Care must be taken in regard to critical conduit oppression by the ventricle in cases with large ventricular volume and/or poor ventricular function.

(243 words) 
Since extracardiac total cavopulmonary connection (EC-TCPC) was first introduced as a definitive procedure for patients with functionally univentricular heart in 1990 [1], many surgeons have adopted this approach as their procedure of choice for the Fontan completion. It has been well established that EC-TCPC has potential advantages over lateral tunnel-type connection. It makes it possible to avoid aortic cross-clamping and atriotomy, therefore allowing for a shorter duration of cardiopulmonary bypass (CPB). Near-optimal laminar flow in the systemic venous pathway means no atrial stretch or arrhythmia in the long-term, although the prosthetic conduit lacks growth potential and patients may be obliged to have lifelong prophylactic anticoagulant therapy [2-4].

In a malpositioned univentricular heart with apicocaval juxtaposition (ACJ), however, the completion of EC-TCPC may be compromised by difficulty in securing an appropriate conduit pathway. When the conduit is positioned behind the apex toward the ipsilateral pulmonary artery (PA), obstruction of the conduit or oppression either on the pulmonary veins, atrium or ventricle is of concern because of the narrow space. On the other hand, when the conduit crosses the midline toward the contralateral PA, a long curved conduit route may cause a kink or serious energy loss.

Little is known about the outcome of the EC-TCPC for ACJ because of the rare morphological features of this alignment. Only one recent clinical investigation has focused on this issue [5] and several others are case or technical reports [6-9]. We therefore set out to examine our experience with EC-TCPC in ACJ and shed some light on the factors which influence the decision on route choice.

\section{Patients and Methods}

\section{Patients}

Between 2001 and 2011, 68 patients underwent EC-TCPC at our two pediatric centers (University of Tsukuba Hospital and Ibaraki Children’s Hospital) following the same management policy. Among them, we retrospectively reviewed the medical records of 10 patients with functional single ventricle and ACJ. Charts were examined for patient demographics including age, weight, diagnosis, conduit route, conduit size, pre- 
and postoperative hemodynamic data, additional cardiac operations, and operative details. Endpoints included take down, thromboembolic events and death. These data were compared with the data of 58 patients without ACJ. The study was approved by the Institutional Review Board at University of Tsukuba Hospital and Ibaraki Children's Hospital, and individual consent for the study was waived owing to its retrospective medical record review design.

\section{Operative Technique}

Based on a careful preoperative evaluation, we chose a conduit route to create the most appropriate cephalad (conduit to the PA) anastomosis which would provide satisfactory fluid dynamics for Fontan circulation. After re-do median sternotomy, dissection around the heart was carefully performed. CPB was established with direct bicaval cannulation. The heart was arrested by aortic cross clamping with cold crystalloid cardioplegia infusion through the aortic root when intracardiac manipulation such as the creation of an atrial septal defect, valve repair or main PA division was required. Otherwise an extracardiac conduit (Gore-Tex®, Stretch Vascular Graft) was anastomosed with the caudal surface of either the right or left PA on the beating heart. In 2 patients the extracardiac conduit was placed between the inferior vena cava (IVC) and the ipsilateral PA behind the ventricle to create the shortest route. In the 8 other patients the conduit was placed between the IVC and the contralateral PA taking a slightly roundabout route. After extensive dissection and mobilization of the IVC at the diaphragmatic level, the caudal end of the conduit was sutured to the transected IVC in an end-to-end fashion. A fenestration was created only in patient No.8 who had a dilated ventricle with poor function.

\section{Postoperative Evaluation}

A routine postoperative evaluation was made by echocardiography, cineangiography and cardiac catheterization about 1 month after surgery and postoperative PA pressure was measured. Some patients underwent cardiac catheterization about 1 year after surgery, but this is not routine. Computed tomography 
(CT) was performed only when follow-up physicians requested it for evaluation.

\section{Anticoagulation}

Anticoagulation therapy with intravenous heparin infusion (200 U/kg/day) was initiated within 12 hours after surgery when hemostasis was secured. Subsequently heparin was replaced by warfarin sodium as soon as the patients resumed oral intake. Thereafter the international normalized ratio of prothrombin time was maintained at 1.5-2.5.

\section{Statistical Analysis}

All of the patients' data were reviewed retrospectively from the database of the University of Tsukuba Hospital and Ibaraki Children's Hospital. Quantitative data are presented as mean \pm standard deviation. Comparisons between the two groups were performed with an unpaired two-tailed t-test for normally distributed variables. Statistical significance was considered at $p$ values less than 0.05 .

\section{Results}

\section{Patient Characteristics}

The characteristics of the patients with ACJ are listed in Table 1. The diagnoses of these patients included the heterotaxy syndrome ( $n=4$, right isomerism in 3 cases, left isomerism in 1), right ventricular type univentricular heart $(n=1)$, double outlet right ventricle $(n=2)$, double inlet left ventricle $(n=1)$, and univentricular heart with indefinite ventricular type $(n=2)$. The mean age at operation was $8 \pm 7$ years (range, 3 - 24), and the mean body weight was $22.1 \pm 14.8 \mathrm{~kg}$ (range, 11.5 - 57.5). Preoperative cardiac catheterization showed adequate hemodynamic data for Fontan-type repair, with Nakata-index of $272 \pm 160$ $\mathrm{mm}^{2} / \mathrm{m}^{2}$ (range, $117-636$ ) and a mean PA pressure of $11 \pm 4 \mathrm{mmHg}$ (range, $6-18$ ). All 10 patients underwent bidirectional cavopulmonary connection before EC-TCPC based on a staged Fontan strategy. There was no significant difference in the preoperative patient characteristics when compared with the 58 
patients without ACJ (Table 2).

\section{Surgical Outcomes}

In the patients with ACJ, the mean CPB time was $196 \pm 67$ minutes (range, 111 - 349 minutes). The heart was arrested only when intracardiac manipulation was required. The diameter of the extracardiac conduit was $16 \mathrm{~mm}$ in 1 patient, $18 \mathrm{~mm}$ in 8 patients, and $20 \mathrm{~mm}$ in 1 patient. The mean postoperative PA pressure was $13 \pm 2 \mathrm{mmHg}$ (range, $11-20 \mathrm{mmHg}$, including the last data on patient No. 8). The median duration of intensive care unit stay was 6 days. The mean follow-up was $40 \pm 28$ months (range, $2-71$ months). These surgical and postoperative data were not significantly different when compared with the patients without ACJ (Table 2). There was no conduit-related reoperation in any patient expect for 1 in whom acute conduit occlusion developed. Postoperative cineangiogram (Fig 1) and CT (Fig 2) showed a curved but unobstructed venous pathway when the conduit was placed between the IVC and the contralateral PA. On the other hand, in a case in which the conduit was positioned behind the apex, CT showed no conduit obstruction or oppression either on the pulmonary veins or ventricle, although slight compression on the atrium was seen (Fig 3).

One young adult patient with double outlet of right ventricle (No.8) developed acute thrombotic occlusion of the conduit on the 8th postoperative day. Despite efforts with surgical thrombectomy and thrombolysis, the patient died due to bleeding and multiple organ dysfunctions within 48 hours. Since the patient had a large and poorly functioning single right ventricle (ejection fraction $41 \%$, diastolic diameter 65mm), an extracardiac TCPC was selected instead of an intracardiac tunnel to avoid cardiac arrest, and a fenestrated conduit was placed between the IVC and the contralateral PA so as to avoid compression behind the enlarged ventricle. Still, the conduit was constricted between the bottom of the enlarged ventricle and the diaphragm. Among the 67 other TCPC cases, none of the patients experienced early or late death, conduit stenosis or pulmonary venous obstruction. 


\section{Comments}

Our experience shows favorable clinical EC-TCPC outcomes in patients with functional single ventricle and ACJ. Nine of 10 patients tolerated EC-TCPC without early mortality, re-exploration, take down or significant morbidity. Either conduit route could be conducted without external compression, pulmonary venous obstruction or thromboembolic event.

Based on our experience, the route between the IVC and the contralateral PA should take precedence over the route behind the ventricle since a space for the conduit placement can be easily secured without flipping over the ventricle or extensive dissection. The biggest concern in this design is a relatively longer and curved conduit which crosses the midline toward the contralateral PA and may therefore lead to a certain amount of energy loss. However, no excessive venous resistance, kinks or thromboembolic events were encountered in this roundabout route in the standard risk cases. We do not think that conduit oppression by the spine is a serious matter because the IVC usually locates anterior to the spine in normal anatomy and even in heterotaxy (Fig 2). Probably the most important factor in choosing the conduit route is the facility in making a satisfactory cephalad anastomosis which provides better fluid dynamics in Fontan circulation. If one of the PAs is good in size without severe adhesion, calcification or previous stenting, and can be exposed widely against the aorta, it is preferable as a site for cephalad anastomosis. The need for pulmonary augmentation can be another inevitable reason in selecting the anastomotic site. A conduit can then be conducted towards the IVC in either way. When both PAs are in equal condition, although route choice depends on space availability and severity of adhesion, it is quite rational to choose the route between the IVC and the contralateral PA with minimal dissection. In this setting, a fenestration can be easily created even after cessation of CPB since the conduit and the atrium are adjacent to each other.

The reasons we chose the route behind the ventricle as exceptions in two of our cases are as follows. In case No.5, there was tight adhesion and calcification at the right PA (contralateral to the IVC) after repeated surgical manipulations in previous PA plasty procedures. In case No.6, the right PA (contralateral to the IVC) was a little smaller than the opposite PA and angled off toward the posterior. In addition, since the enlarged 
ascending aorta was overlying the right PA, it was better to secure a cephalad anastomosis onto the left PA. In both cases, conduit space behind the atrium and ventricle was relaxed by opening the pleural cavity. Maximum efforts were made to avoid pulmonary venous obstruction by aggressive dissection around the pulmonary veins.

In adult patients with dilated ventricles with poor function as in our case No. 8, a conduit route should be created very carefully $[10,11]$. Our choice was not successful since the space between the bottom of the enlarged ventricle and the diaphragm was probably too narrow and therefore the long conduit was compressed and inevitably had a nearly right-angled curve around the IVC anastomotic site. With such conditions, an intraatrial tunnel could be an alternative but such a complex procedure requires aortic cross clamping and cardiac arrest, and therefore may deteriorate ventricular function [12]. Kawahira and colleagues described a modified Fontan technique with a handmade shoetree extracardiac graft which gently bridged the vertebra in a patient with ACJ [8]. The technique may be effective in anastomosing the IVC orifice with the conduit without creating an obstructive venous pathway.

In the literature, there are only a few reports which have addressed the issue of EC-TCPC in patients with ACJ. Surprisingly, these reports and several other case presentations have all come from Japan or South Korea [5-9]. It is well known that there is a higher incidence of heterotaxy in eastern Asia, but there may be a higher incidence of ACJ as well. Previous reports have not clearly mentioned how to decide upon an appropriate conduit route, although Sakurai and colleagues showed that there was no obvious superiority of the pathway behind the ventricle as compared with the pathway crossing the spine. They pointed out that the condition of the anastomotic site, dimension of the apex and need for pulmonary augmentation are important factors in selecting the pathway [5]. In the present report, we clearly state that the route between the IVC and the contralateral PA should be the primary choice as far as there is no concern about PA size and condition since the route is less invasive and technically beneficial. 


\section{Study Limitations}

This is a retrospective, observational study. Although all patients had clear documentation of pre- and postoperative variables, other interesting variables such as pulmonary vascular resistance and dimension of the atrium or ventricle were less well documented and could not be examined in relation to the outcome. As the study covered more than 25 years of experience since first palliation, older patients could be treated on the palliation policy in the early surgical era. Moreover, since the number of ACJ patients for each conduit pathway was small, comparative analyses with regard to outcome for each group could not been performed.

In conclusion, EC-TCPC for patients with functional single ventricle and ACJ can be carried out with favorable mid-term outcomes. The route between the IVC and the contralateral PA should be the primary choice if the PA is in good shape. Care must be taken regarding critical conduit oppression by the ventricle in cases with large ventricular volume and/or poor ventricular function.

\section{Acknowledgment}

The authors wish to thank Joseph H. Gorman, III, MD, University of Pennsylvania for the language review. 


\section{References}

1) Marcelletti C, Corno A, Giannico S, et al. Inferior vena cava-pulmonary artery extracardiac conduit. A new form of right heart bypass. J Thorac Cardiovasc Surg 1995;110:625-32.

2) Marcelletti CF, Iorio FS, Abella RF, et al. Late results of extracardiac Fontan repair. Semin Thorac Cardiovasc Surg Pediatr Card Surg Annu 1999;2:131-42.

3) Tokunaga S, Kado H, Imoto Y, et al. Total cavopulmonary connection with an extracardiac conduit: Experience with 100 patients. Ann Thorac Surg 2002;73:76-80.

4) Schreiber C, Horer J, Vogt M, et al. Nonfenestrated extracardiac total cavopulmonary connection in 132 consecutive patients. Ann Thorac Surg 2007;84:894-9.

5) Sakurai T, Kado H, Nakano T, et al. The impact of extracardiac conduit-total cavopulmonary connection on apicocaval juxtaposition. Eur J Cardiothorac Surg 2010;38:439-44.

6) Hisaoka T, Hiramatsu T, Okamura Y. Total cavopulmonary connection with straight conduit for apicocaval juxtaposition. Gen Thorac Cardiovasc Surg 2009;57:307-9.

7) Kitayama H, Oku H, Matsumoto T, Onoe M. Total cavopulmonary connection using a pedicled pericardial conduit for a patient with apicocaval juxtaposition. Ann Thorac Surg 2001;72:1393-4.

8) Kawahira Y, Nishigaki K, Ueno T. Extracardiac Fontan procedure bridging the vertebra for apicocaval juxtaposition. Ann Thorac Surg 2006;82:350-2.

9) Lim HG, Kim WH, Oh SS, et al. Alternative Fontan connection for apicocaval juxtaposition. Ann Thorac Surg 2005;79:1047-9.

10) Fujii Y, Sano S, Kotani Y, et al. Midterm to long-term outcome of total cavopulmonary connection in high-risk adult candidates. Ann Thorac Surg 2009;87:562-70.

11) Burkhalt HM, Dearani JA, Mair DD, et al. The modified Fontan procedure: early and late results in 132 adult patients. J Thorac Cardiovasc Surg 2003;125:1252-9.

12) Yoshikawa Y, Ishibashi H, Uemura H, Kawahira Y, Yagihara T. Pathologic findings in atrial musculature seven years after the intraatrial tunnel Fontan. Ann Thorac Surg 2002;73:663-4 
Table 1. Patients' Characteristics, and Pre-, Intra and Postoperative Data in Apicocaval Juxtaposition

\begin{tabular}{|c|c|c|c|c|c|c|c|c|c|c|c|c|c|c|}
\hline No. & Diagnosis & $\begin{array}{l}\text { Age } \\
\text { (year) }\end{array}$ & $\begin{array}{l}\text { Weight } \\
(\mathrm{kg})\end{array}$ & $\begin{array}{c}\text { PAI } \\
\left(\mathrm{mm}^{2} / \mathrm{m}^{2}\right)\end{array}$ & $\begin{array}{c}\text { Preop mPAP } \\
\text { (mmHg) }\end{array}$ & $\begin{array}{l}\text { Conduit } \\
\text { (mm) }\end{array}$ & Route & $\begin{array}{l}\text { CPB } \\
(\min )\end{array}$ & $\begin{array}{l}\text { AXC } \\
(\min )\end{array}$ & Fenestration & $\begin{array}{l}\text { Postop mPAP } \\
\text { (mmHg) }\end{array}$ & $\begin{array}{c}\text { Follow Up } \\
\text { (month) }\end{array}$ & Adverse Event & Prognosis \\
\hline 1 & SV, PA, Dextrocardia & 6 & 16.7 & 131 & 15 & 18 & Contra & 208 & 27 & - & 16 & 71 & - & Alive \\
\hline 2 & SV, PA, Situs Inversus & 3 & 14.8 & 158 & 10 & 18 & Contra & 166 & - & - & 11 & 69 & - & Alive \\
\hline 3 & DORV, PS, Situs Inversus & 4 & 13.2 & 117 & 14 & 18 & Contra & 241 & 38 & - & 11 & 58 & - & Alive \\
\hline 4 & SV, PS, Asplenia & 3 & 16.5 & 175 & 18 & 18 & Contra & 234 & 113 & - & 12 & 57 & - & Alive \\
\hline 5 & RV type SV, PA, Situs Inversus & 15 & 37.7 & 296 & 10 & 18 & Ipsi & 156 & - & - & 15 & 63 & - & Alive \\
\hline \multirow[t]{2}{*}{6} & Hypoplastic LV, AVSD, TOF & 5 & 13.2 & 254 & 11 & 18 & Ipsi & 148 & 69 & - & 15 & 18 & - & Alive \\
\hline & Polysplenia & & & & & & & & & & & & & \\
\hline \multirow[t]{2}{*}{7} & SV, PS, Asplenia, Dextrocardia & 12 & 26.5 & 636 & 7 & 18 & Contra & 111 & 44 & - & 13 & 12 & - & Alive \\
\hline & TAPVC Ia & & & & & & & & & & & & & \\
\hline 8 & DORV, TA, PS, Dextrocardia & 24 & 57.5 & 314 & 6 & 20 & Contra & 349 & - & + & (20) & - & $\begin{array}{l}\text { Conduit } \\
\text { Occlusion }\end{array}$ & Dead \\
\hline 9 & DILV, PS & 5 & 11.5 & 207 & 8 & 16 & Contra & 167 & 35 & - & 14 & 10 & - & Alive \\
\hline \multirow[t]{2}{*}{10} & SV, PS, Asplenia, Dextrocardia & 5 & 13.7 & 429 & 14 & 18 & Contra & 157 & 69 & - & 14 & 2 & - & Alive \\
\hline & TAPVC III & & & & & & & & & & & & & \\
\hline
\end{tabular}

AVSD = atrioventricular septal defect; AXC = aortic cross clamp; Contra = IVC-contralateral PA route; DILV = double inlet left ventricle; DORV = double outlet right ventricle;

Ipsi = IVC-ipsilateral PA route; $\quad \mathrm{mPAP}=$ mean pulmonary artery pressure; $\quad$ PA = pulmonary atresia; $\quad$ PAI = pulmonary artery index (Nakata index); PS = pulmonary stenosis; $\quad$ SV = single ventricle;

$\mathrm{TA}=$ tricuspid atresia; $\quad \mathrm{TAPVC}=$ total anomalous of pulmonary venous connection; $\quad$ TOF $=$ tetralogy of Fallot 
Table 2. Comparison of Two Groups Regarding Pre-, Intra- and Postoperative Data

Patients with ACJ Patients without ACJ

$p$ Value

$(\mathrm{n}=10)$

$(\mathrm{n}=58)$

Age (year)

Body Weight (kg)

PAI $\left(\mathrm{mm}^{2} / \mathrm{m}^{2}\right)$

Preoperative mPAP (mmHg)

CPB time (minute)

Diameter of Conduit

$16 \mathrm{~mm}$
$18 \mathrm{~mm}$
$20 \mathrm{~mm}$

Fenestration

Postoperative mPAP (mmHg)

ICU Stay (day)

Follow Up (month)

Adverse Event

$$
8 \pm 7
$$

$22.1 \pm 14.8$

$272 \pm 160$

$11 \pm 4$

$196 \pm 67$

$$
1
$$

8

1

1 (No. 8)

$13 \pm 2$

$6 \pm 2$

$40 \pm 28$

1 (No. 8)

1 (No. 8)
$5 \pm 4$

0.17

$18.4 \pm 7.5$

0.28

$286 \pm 135$

0.57

$11 \pm 5$

0.76

$166 \pm 52$

0.31
6

51

1

4

$14 \pm 3$

0.21

$5 \pm 3$

0.46

$54 \pm 33$

0.13

Death

ACJ = apicocaval juxtaposition; $\quad \mathrm{CPB}=$ cardiopulmonary bypass;

ICU = intensive care unit; $\quad$ mPAP = mean pulmonary artery pressure;

$\mathrm{PAI}=$ pulmonary artery index (Nakata index) 


\section{Figure Legends}

Fig 1. Cineangiogram of the extracardiac conduit shows a curved and unobstructed venous pathway in the inferior vena cava to the contralateral pulmonary artery route in a patient with apicocaval juxtaposition.

Fig 2. Computed tomography image of the extracardiac conduit placed between the inferior vena cava (IVC) and the contralateral pulmonary artery in an asplenia patient with apicocaval juxtaposition (patient No. 10, Two months after surgery). (A to D) Four levels from the cephalad anastomosis to the IVC. The conduit crosses midline but is not oppressed by the spine since the IVC locates anterior to the spine. $(\mathrm{A}=$ atrium; $\mathrm{C}=$ conduit; $\mathrm{PA}=$ pulmonary artery; $\mathrm{PV}=$ pulmonary vein; $\mathrm{V}=$ ventricle)

Fig 3. Computed tomography image of the extracardiac conduit placed between the inferior vena cava (IVC) and the ipsilateral pulmonary artery in a patient with apicocaval juxtaposition (patient No. 5, Seven years after surgery). (A, B) Cephalad portion of the conduit locates between the atrium and the pulmonary veins. The conduit slightly presses the atrium but not the pulmonary veins. (C, D) Caudal portion of the conduit near the IVC. The conduit has no contact with the ventricle throughout the route. $(\mathrm{A}=$ atrium; $\mathrm{C}=$ conduit; $\mathrm{PV}=$ pulmonary vein; $\mathrm{V}=$ ventricle) 
MORIZUMI ET AL

TCPC IN APICOCAVAL JUXTAPOSITION

Figure 1

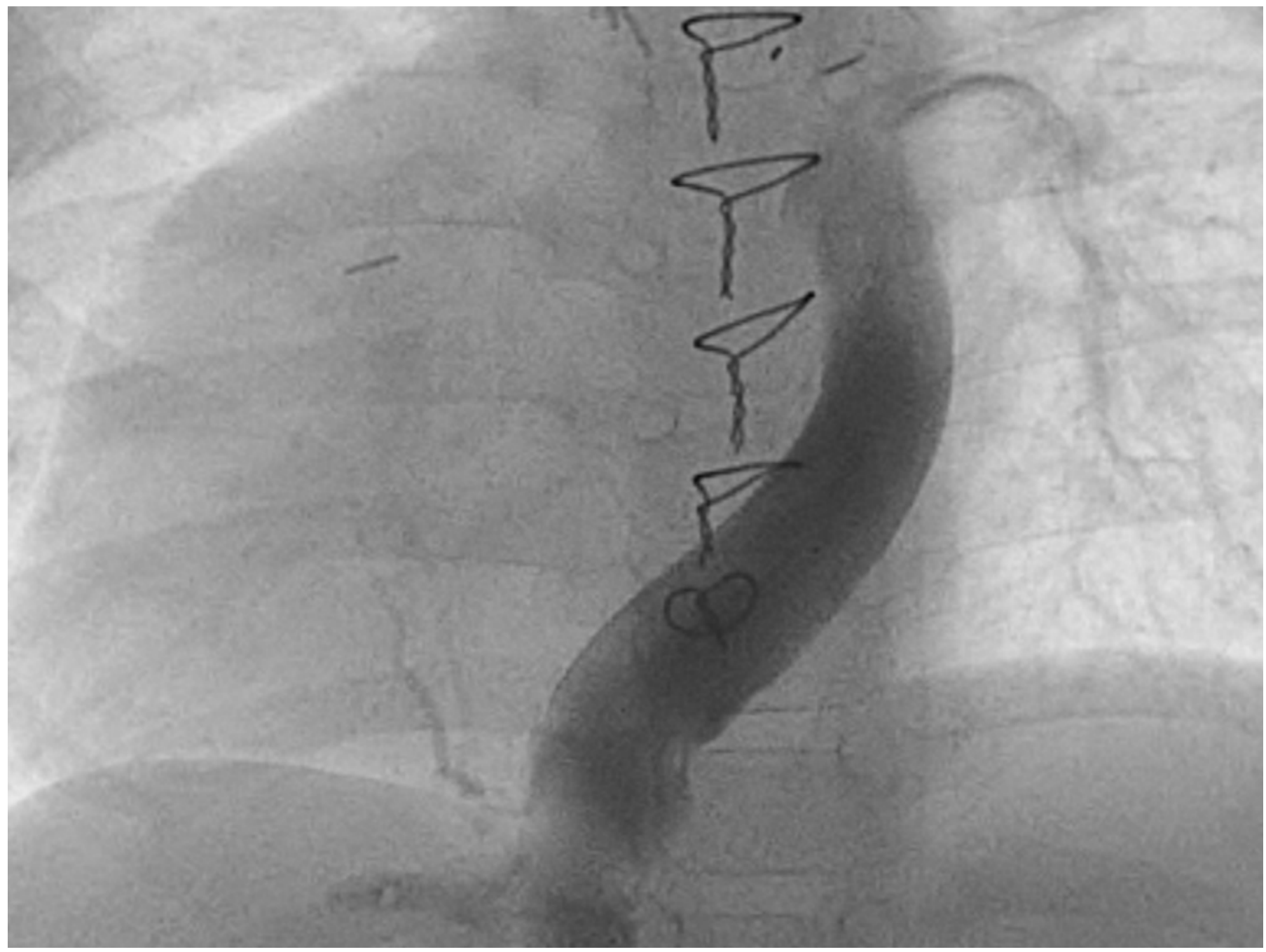


Figure 2

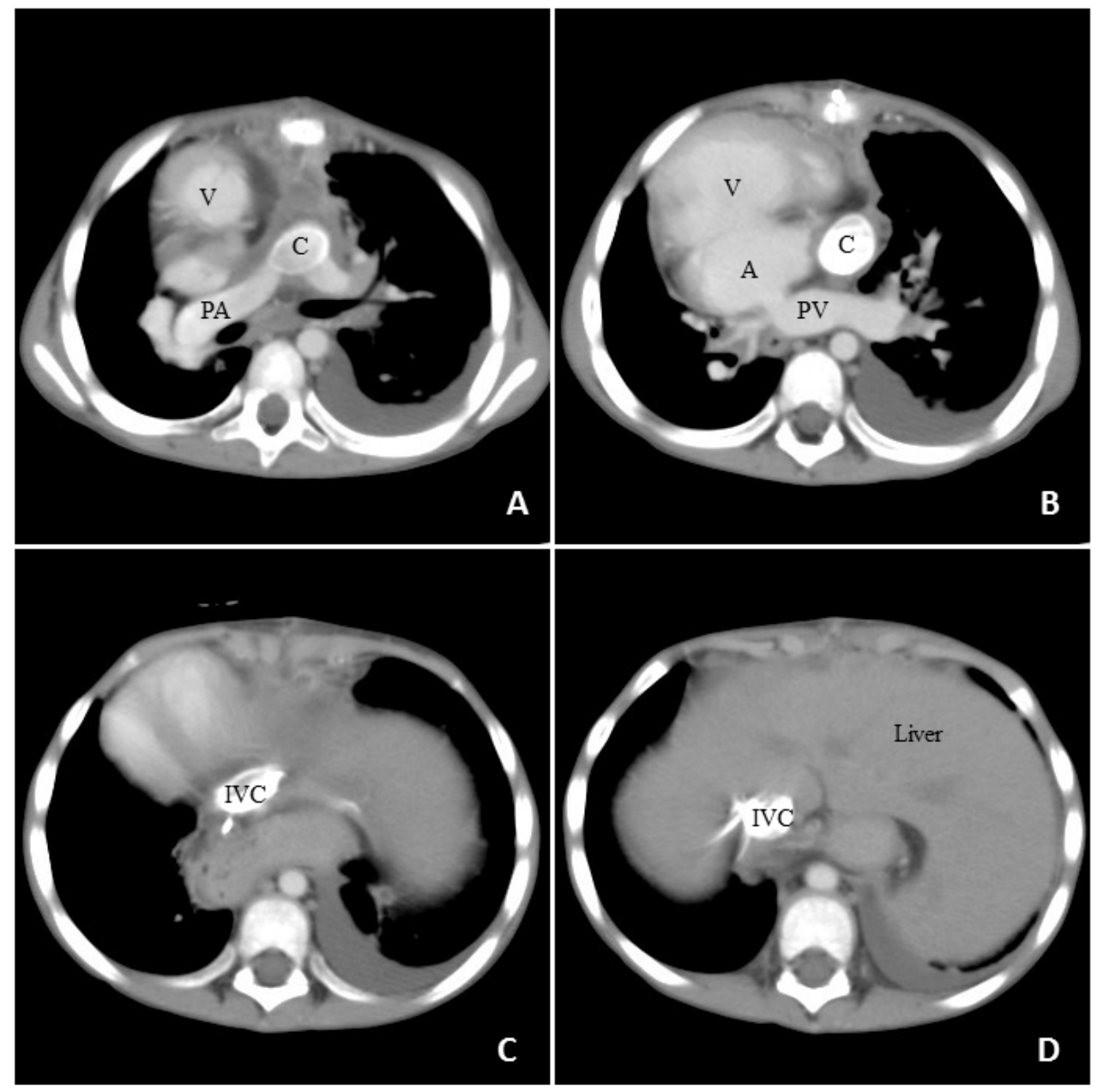


Figure 3
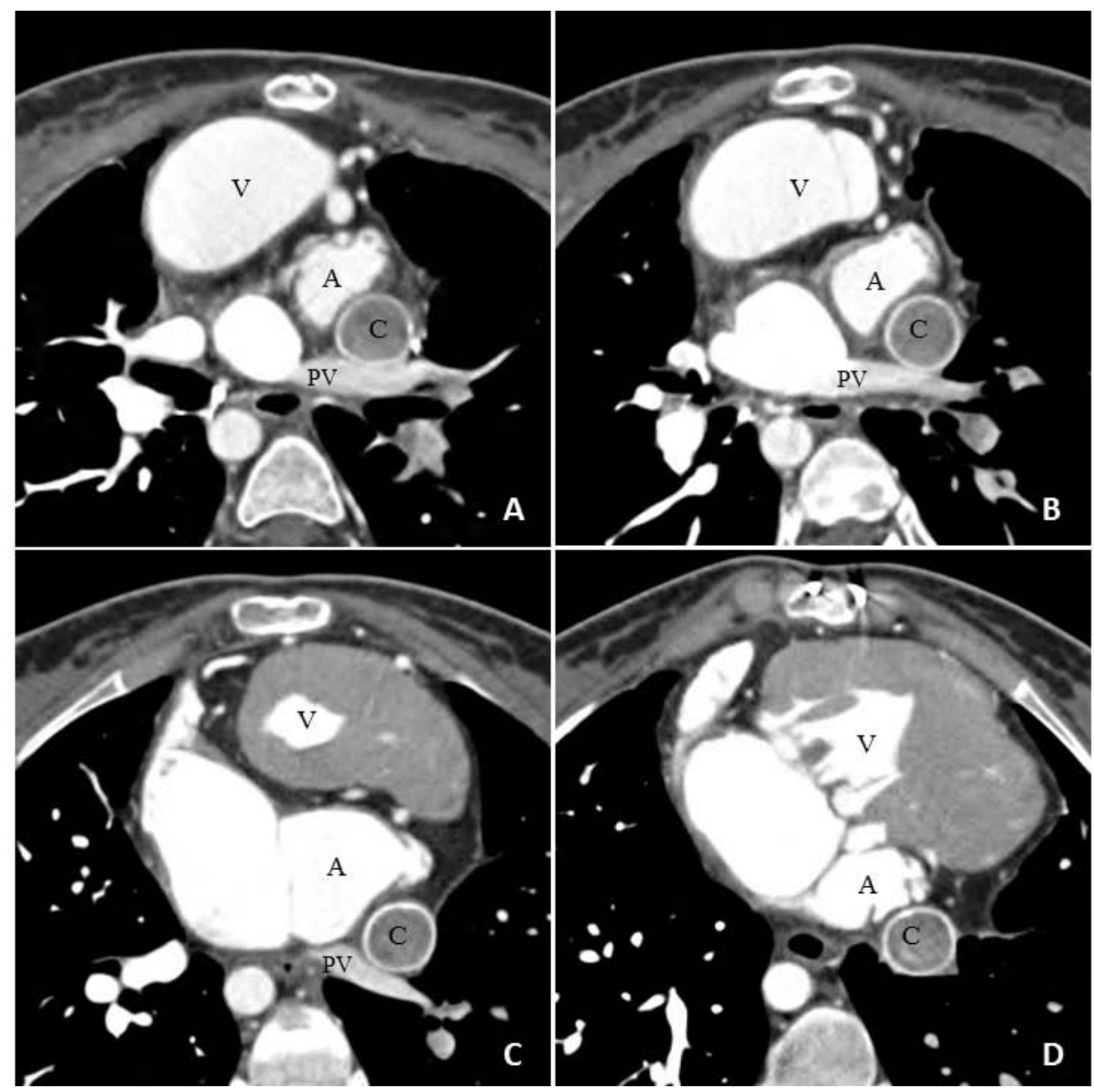